\title{
Analysis of Cesarean Section Indications According to the Robson Classification in Surgical Maternities in Dakar, Senegal: About 9185 Cases
}

\author{
Taliana Stephie Gondjout ", Omar Gassama, Mohamed Tété Diadhiou, Marie Edouard Faye Dieme, \\ Mamour Gueye, Abdoul Aziz Diouf, Pape Malick Ngom, Saidou Diallo, Raymond Alipio, \\ Dieynaba Ndao, Sedouma Yatera, Alphousseyni Gaye, Daouda Ndour, Youanidou Wane Dia, \\ Philippe Marc Moreira, Alassane Diouf, Jean Charles Moreau
}

Gynaecological and Obstetric Clinic, Aristide Le Dantec University Hospital, Dakar, Senegal

Email address:

gondjout@gmail.com (T. S. Gondjout)

${ }^{*}$ Corresponding author

\section{To cite this article:}

Taliana Stephie Gondjout, Omar Gassama, Mohamed Tété Diadhiou, Marie Edouard Faye Dieme, Mamour Gueye, Abdoul Aziz Diouf, Pape Malick Ngom, Saidou Diallo, Raymond Alipio, Dieynaba Ndao, Sedouma Yatera, Alphousseyni Gaye, Daouda Ndour, Youanidou Wane Dia, Philippe Marc Moreira, Alassane Diouf, Jean Charles Moreau. Analysis of Cesarean Section Indications According to the Robson Classification in Surgical Maternities in Dakar, Senegal: About 9185 Cases. Journal of Gynecology and Obstetrics. Vol. 8, No. 5, 2020, pp. 135-140. doi: 10.11648/j.jgo.20200805.12

Received: August 29, 2020; Accepted: September 17, 2020; Published: September 30, 2020

\begin{abstract}
Background: The caesarean section rate remains relatively high in the surgical maternity hospitals in Dakar and the indications for scarred uterus are still high. The management of induced prematurity for maternal pathologies still poses real problems in Dakar. The aim of our study is to compare the Caesarean section rate in the different surgical facilities in Dakar. We used the ROBSON's classification to evaluate the indications for Caesarean section in surgical maternity hospitals in Dakar. Methods: This was a descriptive and analytical prospective study which took place from January $1^{\text {st }}$ to December $31^{\text {st }} 2019$ in 10 surgical maternity hospitals in Dakar (University hospital Aristide Le Dantec, National Hospital Center of Pikine, Municipal Hospital Center Abass NDAO, Principal Hospital of Dakar, Youssou Mbargane DIOP Hospital in Rufisque, Ouakam Military Hospital, Grand Yoff General Hospital, Gaspard Kamara Health Center, Nabil Choucair Health Center, Roi Baudoin Hospital Center) and which included all patients who delivered by caesarean section. Indications for Caesarean section were classified according to ROBSON's 10 group classification. The parameters studied were age, frequency, indications for Caesarean section in these surgical maternity hospitals and, Apgar score at five minutes and, birth weight. Data collection was done through birth records and registers, on-call diaries and integrated into a database developed with Sphinx software. Statistical analysis was done using SPSS software. Results: During the period of the study we recorded 35287 deliveries with 9185 Caesarean sections, i.e. a frequency of $26 \%$. The average age of the patients was 29 years. Indications for Caesarean section in Dakar surgical maternity hospitals were dominated by group 5 (28.4\%) according to Robson's classification. Group 10 in Robson's classification was predominant in the maternity hospitals of University hospital Aristide Le Dantec (23.3\%) and Municipal Hospital Center Abass NDAO (22.5\%). Group 5 was found in the maternity units of the Gaspard Kamara Health Center (32.3\%), Nabil Choucair Health Center (39\%), Principal Hospital of Dakar (26.4\%), Youssou Mbargane Hospital Diop Hospital in Rufisque (31.4\%), Roi Baudoin Hospital Center (29.8\%), Grand Yoff General Hospital (32\%), Ouakam Military Hospital (34.2\%), and, National Hospital Center of Pikine (27.9\%). 4 facilities had a caesarean section rate higher than 30\% (University hospital Aristide Le Dantec 35.6\%, Youssou Mbargane Diop Hospital in Rufisque 32.03\%, Municipal Hospital Center Abass Ndao 32.01\% and, National Hospital Center of Pikine 30.45\%). The average birth weight of new-borns was 2943 grams, with an average Apgar score of 8 at the fifth minute. The post-op care was simple. Conclusion: The caesarean section rate remains relatively high in the surgical maternity hospitals in Dakar and the indications for scarred uterus are still high.
\end{abstract}

Keywords: Caesarean Section, ROBSON Classification, Maternity, Dakar 


\section{Introduction}

Since 1985, the international health community has considered the ideal C-section rate to be between $10 \%$ and $15 \%$. Since that time, Caesarean sections have been increasingly performed in both developed and developing countries. When medically justified, Caesarean section can effectively prevent maternal and perinatal mortality and morbidity. However, there is no evidence that Caesarean delivery has a beneficial effect on women or infants when it is not necessary [1]. Robson proposes an easy-to-use 10group classification that allows comparison of Caesarean section indications worldwide [2].

The aim of our study is to compare the Caesarean section rate in the different surgical facilities in Dakar, to make an analysis according to Robson's classification.

\section{Methods}

\subsection{Type and Period of Study}

This was a descriptive and analytical prospective study which took place from January 1st to December 31st 2019 in 10 surgical maternity hospitals in Dakar (University hospital Aristide Le Dantec, National Hospital Center of Pikine, Municipal Hospital Center Abass Ndao, Principal Hospital of Dakar, Youssou Mbargane DIOP Hospital in Rufisque, Ouakam Military Hospital, Grand Yoff General Hospital, Gaspard Kamara Health Center, Nabil Choucair Health Center, Roi Baudoin Hospital Center).

\subsection{Inclusion Criteria and Parameters Studied}

All patients who delivered by caesarean section, vaginal deliveries with a gestational age greater than 22 weeks. Patients were classified into 10 groups according to Robson's classification, using maternal characteristics and obstetrical history. The parameters studied were age, frequency, indications for Caesarean section in these surgical maternities, Apgar score at five minutes, and birth weight. The different parameters of the classification are presented in Table 1.

Table 1. Obstetrical characteristics of parturients in Robson's classification [2].

\begin{tabular}{ll}
\hline Group & Descriptions \\
\hline 1 & Nulliparous, single cephalic, $\geq 37$ weeks, in spontaneous labor \\
2 & $\begin{array}{l}\text { Nulliparous, single cephalic, } \geq 37 \text { weeks, induced or CS before } \\
\text { labor }\end{array}$ \\
& $\begin{array}{l}\text { Multiparous (excluding previous CS), single cephalic, } \geq 37 \\
\text { weeks, in spontaneous labor }\end{array}$ \\
4 & Multiparous (excluding previous CS), single cephalic, $\geq 37$ \\
5 & weeks, induced or CS before labor \\
6 & Previous CS, single cephalic, $\geq 37$ weeks \\
7 & All nulliparous breeches \\
8 & All multiparous breeches (including previous CS) \\
9 & All abnormal lies (including previous CS) \\
10 & All single cephalic, $\leq 37$ weeks (including previous CS) \\
\hline
\end{tabular}

\subsection{Exclusion Criteria}

Spontaneous vaginal deliveries or instrumental extractions.

\subsection{Data Collection and Analysis}

Data collection was done through birth records and registers, duty report books and integrated into a database developed with Sphinx software. Statistical analysis was done using SPSS software.

\section{Results}

\subsection{Descriptions}

During this study, the total number of deliveries was 35,287 of which 9,185 were Caesarean sections with a Caesarean section rate of $26 \%$.

Table 2. Distribution of Caesarean section rate according to each structure.

\begin{tabular}{llll}
\hline Hospitals & Number of births in 2019 & Number of Caesarean sections & Caesarean section frequency (\%) \\
\hline University hospital Aristide Le Dantec & 2218 & 791 & 35,70 \\
Gaspard Kamara Health Center & 4301 & 1077 & 25,04 \\
Roi Baudoin Hospital Center & 5090 & 1013 & 19,90 \\
National Hospital Center of Pikine & 5723 & 1743 & 30,45 \\
Principal Hospital of Dakar & 2978 & 804 & 26,70 \\
Youssou Mbargane DIOP Hospital in Rufisque & 3265 & 1046 & 32,04 \\
Nabil Choucair Health Center & 5044 & 864 & 17,13 \\
Grand Yoff General Hospital & 2016 & 462 & 22,91 \\
Ouakam Military Hospital & 1313 & 316 & 24,00 \\
Municipal Hospital Center Abass Ndao & 3339 & 1069 & 32,01 \\
Total & 35287 & 9185 & \\
\hline
\end{tabular}

The study involved 10 health facilities for 9185 Caesarean sections. National Hospital Center of Pikine recorded (18.9\%) the highest number of cases (1,743 caesarean sections). Figure 1 illustrates the Caesarean section rate of each facility as a function of the total number of Caesarean sections recorded by the 10 facilities.
The Caesarean section rate in each structure is shown in Table 2. The highest number of C-sections was recorded at University hospital Aristide Le Dantec (35.7\%), followed by Youssou Mbargane Diop Hospital in Rufisque (32.04\%) and Municipal Hospital Center Abass Ndao (32.01\%) as reported in Table 2. 


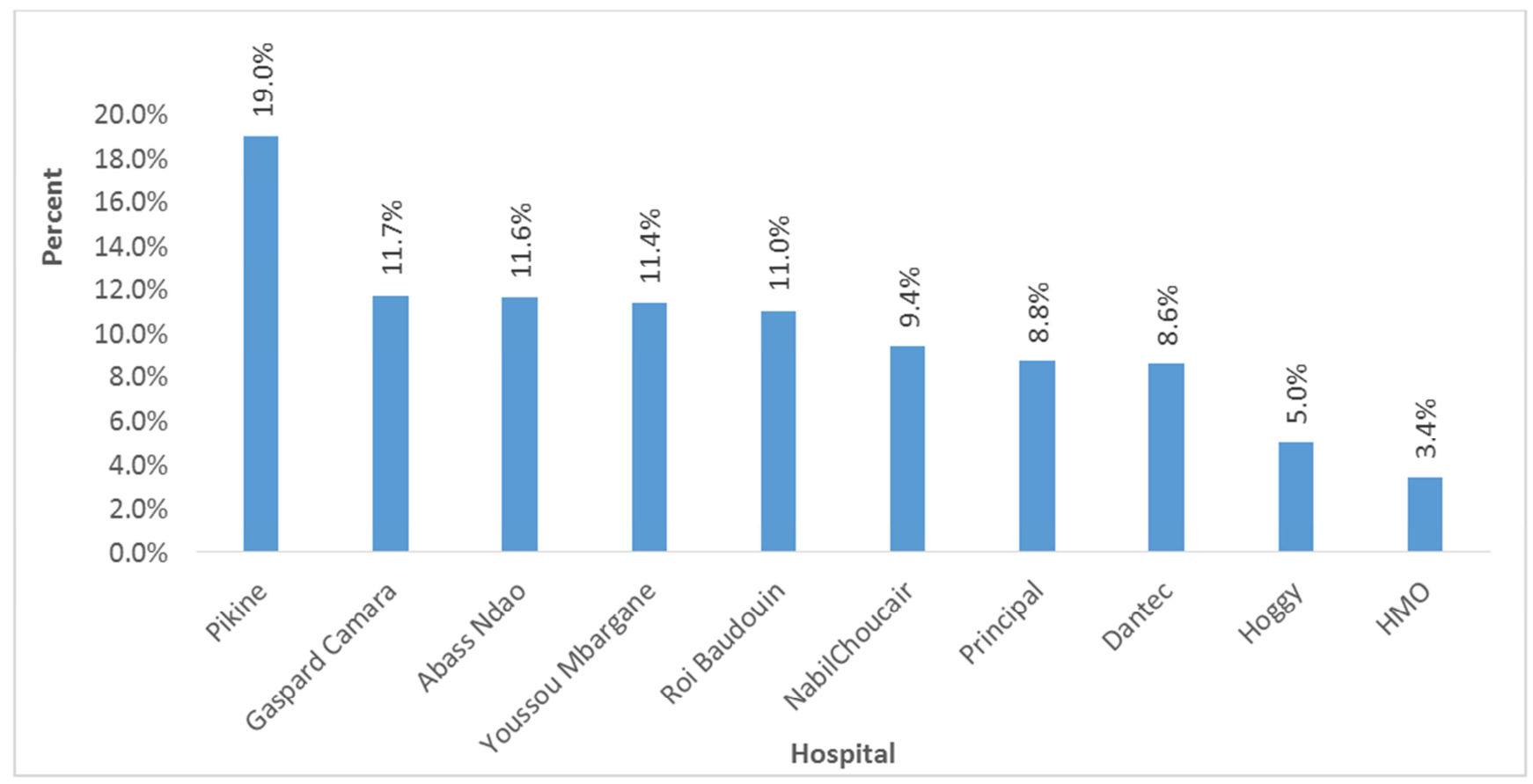

Figure 1. Distribution of C-section rate by type of structure.

\subsection{Socio-demographic Characteristics}

1. Age

The average age of the patients was 29 years with extremes of 13 and 49 years. In our series the majority of patients (44.6\%) were between 20-29 years of age as reported in Figure 2.

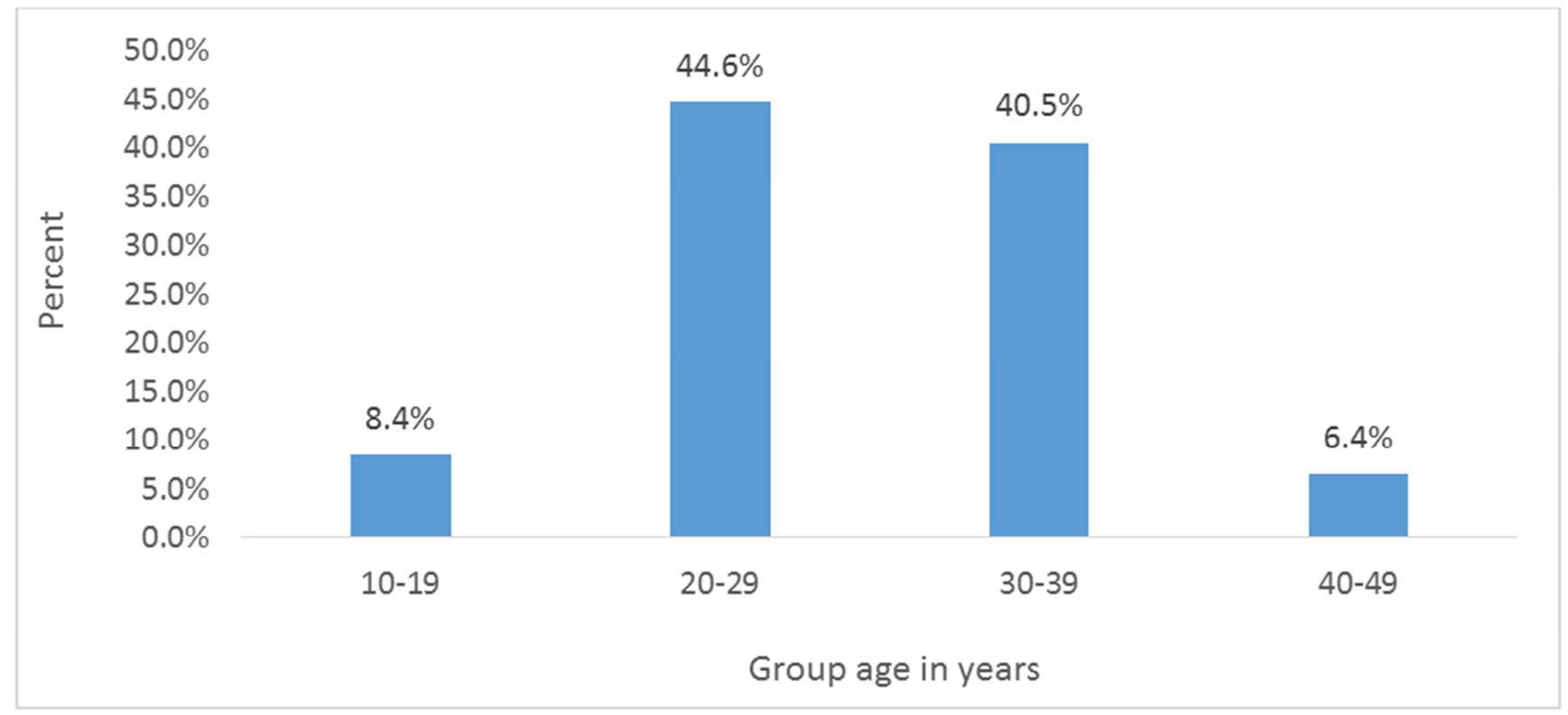

Figure 2. Distribution of Patients by Age Group.

2. Indications for Caesarean section

According to Robson's classification, Group 5 is the most represented (28.4\%), followed by Group 1 (16.7\%) and, Group 2 (13.2\%). Figure 3 illustrates the results. 


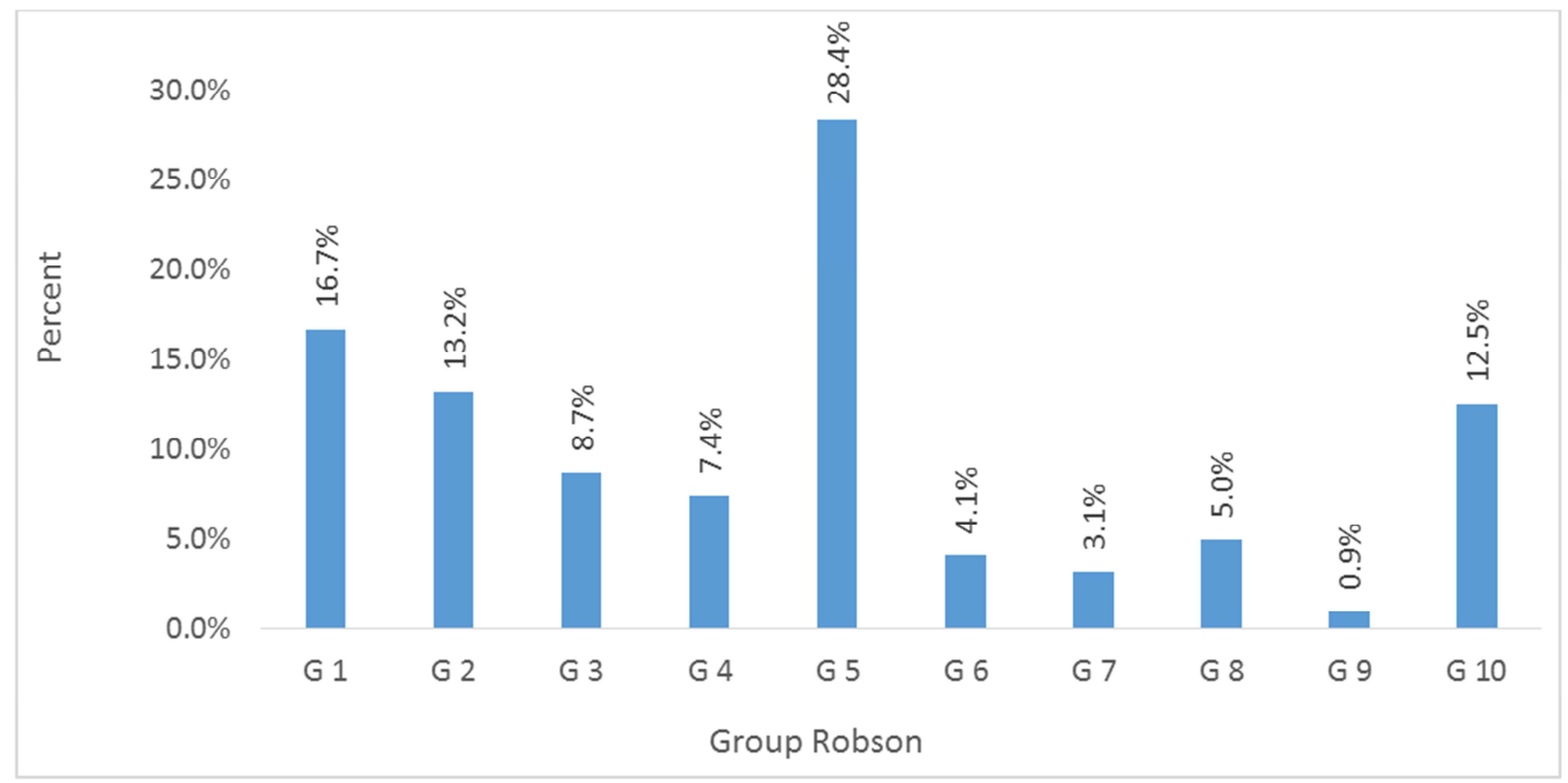

Figure 3. Breakdown into 10 groups according to Robson's classification.

We noted that group 10 is the most represented in level 3 maternity facilities (University hospital Aristide Le Dantec, Municipal Hospital Center Abass Ndao, Principal Hospital of Dakar and, National Hospital Center of Pikine) with rates of $23.5 \%, 22.5 \%, 17.8 \%$ and $20.2 \%$ respectively.

In level 2 maternity hospitals such as Nabil Choucair Health Center and, Gaspard Kamara Health Center, Robson's group 5 was predominant with rates of $39 \%$ and $32.3 \%$ respectively.

In our series the frequency of Caesarean section in Robson's group 1 was 24.7 at the Roi Baudoin Hospital Center and $21.1 \%$ at Youssou Mbargane DIOP Hospital in Rufisque as reported in Table 3.

Table 3. Distribution of caesarean section rate by group in surgical maternity hospitals.

\begin{tabular}{|c|c|c|c|c|c|c|c|c|c|c|c|}
\hline Hospitals & G1 & G2 & G3 & G4 & G5 & G6 & G7 & G8 & G9 & G10 & Percentage \\
\hline Municipal Hospital Center Abass Ndao & $13,8 \%$ & $15,2 \%$ & $7,1 \%$ & $10,7 \%$ & $19,6 \%$ & $3,5 \%$ & $2,4 \%$ & $4,0 \%$ & $1,2 \%$ & $22,5 \%$ & $100 \%$ \\
\hline University hospital Aristide Le Dantec & $15,8 \%$ & $13,9 \%$ & $7,8 \%$ & $6,6 \%$ & $15,9 \%$ & $4,2 \%$ & $3,4 \%$ & $7,7 \%$ & $1,4 \%$ & $23,3 \%$ & $100 \%$ \\
\hline Gaspard Kamara Health Center & $14,4 \%$ & $20,9 \%$ & $6,5 \%$ & $9,4 \%$ & $32,3 \%$ & $4,3 \%$ & $3,8 \%$ & $3,4 \%$ & $1,4 \%$ & $3,6 \%$ & $100 \%$ \\
\hline Grand Yoff General Hospital & $13,2 \%$ & $13,6 \%$ & $10,8 \%$ & $8,2 \%$ & $32,0 \%$ & $4,6 \%$ & $3,0 \%$ & $4,1 \%$ & $1,3 \%$ & $9,2 \%$ & $100 \%$ \\
\hline Nabil Choucair Health Center & $18,1 \%$ & $11,1 \%$ & $10,1 \%$ & $6,8 \%$ & $39,0 \%$ & $3,8 \%$ & $2,4 \%$ & $4,4 \%$ & $0,8 \%$ & $3,5 \%$ & $100 \%$ \\
\hline National Hospital Center of Pikine & $17,3 \%$ & $9,4 \%$ & $9,1 \%$ & $5,6 \%$ & $27,9 \%$ & $4,1 \%$ & $3,2 \%$ & $5,1 \%$ & $0,5 \%$ & $17,8 \%$ & $100 \%$ \\
\hline Roi Baudoin Hospital Center & $24,7 \%$ & $9,9 \%$ & $10,8 \%$ & $5,4 \%$ & $29,8 \%$ & $4,8 \%$ & $4,0 \%$ & $3,9 \%$ & $0,6 \%$ & $6,1 \%$ & $100 \%$ \\
\hline $\begin{array}{l}\text { Youssou Mbargane DIOP Hospital in } \\
\text { Rufisque }\end{array}$ & $21,1 \%$ & $9,4 \%$ & $11,1 \%$ & $6,3 \%$ & $31,5 \%$ & $5,1 \%$ & $2,8 \%$ & $6,3 \%$ & $1,1 \%$ & $5,3 \%$ & $100 \%$ \\
\hline
\end{tabular}

3. Neonatal Data

The weight of the new-born was 2943.26 grams, with an Apgar score averaging 7.9.

\section{Discussion}

\subsection{Frequency of Caesarean Section}

Caesarean section is the most performed surgical procedure worldwide. Its indication is classified according to different reasons (maternal, adnexal and, mixed), which makes it difficult to compare indications with other structures. In 2001 Dr Michael Robson proposed a classification in 10 groups, which are simple to use and read. These 10 groups include parity; presentation; gestational age; history of Caesarean section; number of foetuses; spontaneous labour or induction [2].

Robson's classification is a method of evaluating and comparing factors that contribute to Caesarean section rates and their effects.

It also allows comparisons to be made between institutions, regions, and countries that use such a system.

The main advantages of this classification system include its simplicity and clinical relevance. Also, this system uses mutually exclusive population classes based on maternal characteristics that are usually routinely collected in all maternity hospitals when women are admitted for delivery [2]. It is a classification that is simple to use and reproducible, and can thus be used as a reference tool to make comparisons between maternity hospitals, regions and even countries, 
while limiting interpretation bias [3, 4].

The Caesarean section rate is $4.4 \%$ in Senegal, with a disparity between regions and the capital, where some facilities have a rate of more than $35 \%$ [5]. In our study the average $\mathrm{C}$-section rate was $26 \%$ in Dakar. Our rate is different from that found by Mbungu in the Democratic Republic of Congo which had a rate of $18 \%$ while Mac Dorman in America, Ronsmans in Asia and Torloni in Europe had respectively a rate of $35 \%, 27 \%, 38 \%$ [6-9].

In Senegal the caesarean section rate is higher in level 3 maternity hospitals such as University hospital Aristide Le Dantec (35.7\%) or the, Youssou Mbargane Diop Hospital in Rufisque (32.04\%), the National Hospital Center of Pikine $(30.45 \%)$. This high frequency can be explained by the fact that the majority of evacuated parturients have dystocia requiring an emergency caesarean section for maternal or foetal reasons.

\subsection{Age of Parturients}

In our series the average age of the patients was 29 years with one of the extremes of 13 and 49 years. In our series the majority of patients (44.73\%) were between 20-29 years of age. Other studies conducted under the same socio-economic conditions had found a mean age of 27 years [10].

\subsection{Indications for Caesarean Section}

Cragnin's 1916 aphorism, "Caesarean section once, Caesarean section always", has certainly been questioned for a long time; however, iterative Caesarean section for scarred uterus is still common, especially in the United States [11].

With an overall contribution of $28.37 \%$, Group 5 (scarred uterus) is a major contributor to our overall Caesarean section rate. The same finding worldwide shows that history of Caesarean section is the leading cause of repeat Caesarean section [12]. However, there is a large body of evidence that shows a satisfactory lower C-section success rate of $60-90 \%[13,14]$. The management of natural birth after C-section appears to be one of the most effective mechanisms for slowing the progression of the overall $\mathrm{C}$ section rate [15]. This should be all the more important since the perinatal outcome with natural birth after $\mathrm{C}$ section is better than with elective Caesarean section in singleton pregnancies [16]. Other expected benefits of the lower route are a length of hospital stay halved and reduced hospitalization costs [17]. The major problem with scarred uteri is the risk of uterine rupture, estimated in the literature to be less than $1 \%$ [16].

According to a systematic review by Guise et al, 370 Caesarean sections would be necessary to avoid 1 case of symptomatic uterine rupture and 7142 Caesarean sections would be necessary to avoid 1 foetal death from rupture. Although the risk is low, obstetricians and their patients are less likely to attempt a lower route because they believe that iterative Caesarean section is safer [15]. However, the co-morbidities associated with Caesarean section (thromboembolic complications, infection, etc.) are often not taken into account.
The rehabilitation of childbirth on a scarred uterus requires the development of strategies to select patients at low risk of uterine rupture during an attempted vaginal delivery. Ultrasound measurement of the lower segment is one of the tools used to reassure the obstetrician and the patient. Rozenberg reported in a prospective study (642 patients) that the risk of scarring dehiscence was almost zero (NPV 99.3\%) when the lower segment was $>3.5 \mathrm{~mm}$ [17]. This correlation between segment thickness and risk of uterine rupture was subsequently confirmed in several studies $[18,19]$. However, prospective randomized trials are still needed to determine a standardized measurement technique and a discriminating cut-off in order to validate this attitude in clinical practice. The thickness of the lower segment alone cannot constitute the indication or contraindication for vaginal delivery, as the overall obstetric context must always take precedence.

Group 1 is the largest and most important obstetrical group and its Caesarean section rate is directly related to the management of nulliparous women in spontaneous labour [1]. Our Caesarean section rate in this group $(12.6 \%)$ is comparable to those observed in Finland or Iceland [20].

\subsection{Neonatal Prognosis}

In our series, the weight of the new-born was 2943.26 grams, with an Apgar score averaging 7.9. The prognosis of the new-borns in our study corresponds to that of the other series [21].

\section{Conclusion}

The aim of our study was to compare the Caesarean section rate in the different surgical facilities in Dakar.

The caesarean section rate in Dakar 26\% is high compared to WHO recommendations. The groups most at risk are 5 and 1. The main reasons are the history of Caesarean section for group 5 and the fetopelvic disproportion and foetal hypoxia for group 1. Thus, analysis of the various factors that may influence the Caesarean section rate in these groups $(5,1,2$ and 10) will enable us to implement strategies to reduce this rate in our communities. Robson's classification is easy to use and should be implemented in the different structures to allow analysis and comparisons of Caesarean section indications.

\section{Abbreviation}

SPSS: Statistical Package for the Social Sciences

CS: Caesarean section

\section{Funding}

No funding sources.

\section{Conflict of Interest}

The authors declare that they have no competing interests. 


\section{Ethical Approval}

The study was approved by the Institutional Ethics Committee (Protocol 021/2020/CER/UCAD-Reference: CER/UCAD/AD/MSN/026/2020).

\section{References}

[1] Organisation Mondiale de la Sante. Déclaration de l'OMS sur les taux de césarienne. Organisation mondiale de la Santé; 2015.

[2] Robson MS Classification of caesarean sections. Fetal and Maternal Medicine Review 2001; 12: 23-39.

[3] Brennan D, Robson M, Murphy M, O’Herlihy C Comparative analysis of international cesarean delivery rates using 10 group classification in spontaneous labor. Am J Obstet Gynecol 2009; 201: 308 [e1-e8].

[4] Delbaere I, Cammu H, Mertins E, Tency I, Martens G, Temmerman M. Limiting the cesarean section rate (in low risk pregnancies is key to lowing the trend of increased abdominal delivery). BMC Pregnancy Child birth, An observational Study 2012; 12: 3p.

[5] Enque te Démographique et de Santé Continue (EDSContinue) 2014. Agence Nationale de la Statistique et de la Démographie (ANSD) Dakar, Sénégal, 2015, 74p.

[6] Mbungu MR, Ntela MJ, Kahindo MP. Fréquence des césariennes selon la classification de Robson dans 3 maternités de la ville de Kinshasa, en République Démocratique du Congo Prevalence of caesarean according to the Democratic Republic of Congo. Ann Afr Méd. 2017; 10 (2).

[7] MacDorman MF, Menacker F, Declercq E. Cesarean birth in the United States: epidemiology, trends, and outcomes. Clin Perinatol 2008. Jun; 35 (2): 293-307.

[8] Ronsmans C, S. Holtz, and C. Stanton, Socioeconomic differentials in caesarean rates in developing countries: a retrospective analysis. TheLancet, 2006; 368 (9546): 15161523.

[9] Torloni MR, Daher S, Betran AP, Widner M, Montilla P, Souza JP et al. Portrayal of caesarean review. BMJ 2011; 342: d276.

[10] Moussa Diallo, Marie Edward Faye Dieme, Omar Gassama, Astou Coly Niassy Diallo, Mame Diarra Ndiaye Gueye, Jean Charles Moreau. The Caesarean Section in Dakar: Indications and Analysis Prognosis. Open Journal of Obstetrics and $\begin{array}{lrr}\text { Gynecology, 2019, } & 9, & 1213-1220 \\ \text { https://www.scirp.org/journal/ojog. } & & \text { DOI: } \\ \text { 10.4236/ojog.2019.99118. } & \end{array}$

[11] Flamm BL, Newman LA, Thomas SJ, Fallon D, Yoshida MM. Vaginal birth after cesarean delivery: result of a 5 year multicenter collaborative study. Obstet Gynecol 1990; 76: 750-4.

[12] Brennan DJ, Robson MS, Murphy M, O'Herlihy C. Comparative analysis of international cesarean delivery rates using 10-group classification identifies significant variation in spontaneous labor. Am J Obstet Gynecol 2009; 201: 308, e1-8.

[13] Studsgaard A, Skorstengaard M, Glavind J, Hvidman L, Uldbjerg N. Trial of labor compared to repeat cesarean section in women with no other risk factors than a prior cesarean delivery. Acta Obstet Gynecol Scand 2013; 92: 1256-63.

[14] Guise JM, Berlin M, McDonagh M, et al. Safety of vaginal birth after cesarean: a systematic review. Obstet Gynecol 2004; 103: 420-9.

[15] Tilden EL, Cheyney M, Guise JM, et al. Vaginal birth after cesarean: neonatal outcomes and United States birth setting. Am J Obstet Gynecol 2017; 216: 403, e1-e8.

[16] Guise JM, Eden K, Emeis C, et al. Vaginal birth after cesarean: new insights. Evid Rep Technol Assess (Full Rep) 2010: 1-397.

[17] DiMaio H, Edwards RK, Euliano TY, Treloar RW, Cruz AC. Vaginal birth after cesarean delivery: an historic cohort cost analysis. Am J Obstet Gynecol 2002; 186: 890-2.

[18] Rozenberg P, Goffinet F, Phillippe HJ, Nisand I. Ultrasonographic measurement of lower uterine segment to assess risk of defects of scarred uterus. Lancet 1996; 347: 2814.

[19] Jastrow N, Demers S, Chaillet N, et al. Lower uterine segment thickness to prevent uterine rupture and adverse perinatal outcomes: a multicenter prospective study. Am J Obstet Gynecol 2016; 215: 604e1-e6.

[20] FukudaK, ShimizuT, Bujold E. Ultrasound assessment of lower uterine segment thickness during pregnancy, labour, and the postpartum period. J Obstet Gynaecol Can 2016; 38: 13440.

[21] Pyykonen A, Gissler M, Lokkegaard E, et al. Cesarean section trends in the Nordic countries - a comparative analysis with the Robson classification. Acta Obstet Gynecol Scand 2017; 96: 607-16.

[22] C. T. Cisse, E. Ewagnignon, I. Terolbe, F. Diadhiou. Accouchement sur utérus cicatriciel au CHU de Dakar. J Gynecol Obstet Biol Reprod 1999; 28: 556-562. 